\title{
Lotteries vs. All-Pay Auctions in Fair and Biased Contests ${ }^{1}$
}

\author{
Gil S. Epstein \\ Bar-Ilan University, CReAM, London and IZA, Bonn \\ Yosef Mealem \\ Netanya Academic College, Netanya, Israel \\ Shmuel Nitzan \\ Bar-Ilan University
}

\begin{abstract}
The form of contests for a single fixed prize can be determined by a designer who maximizes the contestants' efforts. This paper establishes that, under common knowledge of the two asymmetric contestants' prize valuations, a fair Tullock-type endogenously determined lottery is always superior to an all-pay-auction; it yields larger expected efforts (revenues) for the contest designer. If the contest can be unfair (structural discrimination is allowed), then the optimal lottery cannot be dominated by an all-pay-auction.
\end{abstract}

Keywords: contest design, efforts (revenue) maximization, discrimination, endogenous lottery, all-pay auction.

JEL Classification: D70, D71,D72

\footnotetext{
${ }^{1}$ Financial support from the Adar Foundation of the Economics Department at Bar-Ilan University is gratefully acknowledged.
} 


\section{Introduction}

Many economic and political decisions are the outcome of all-pay strategic contests for a given prize. In such contests the single winner depends on the efforts invested by the contestants. Applications of these contests include promotional competitions, litigation, internal labor market tournaments, rent-seeking, R\&D races, political and public policy competitions and sports, Epstein and Nitzan (2007), Konrad (2009), Congleton et al. (2008). Endogenous determination of such contests may involve all of their relevant institutional characteristics. These are typically determined by contest designers; economic and political entrepreneurs who wish to maximize the efforts made by the contestants. Most of the literature on optimal contest design has focused on the choice of the contest prize, Glazer and Hassin (1988), Runkel (2006), Singh and Wittman (1998), Epstein and Nitzan (2002), (2006a), (2006b), (2007), the set of contestants, Baye et al. (1993), Amegashie (2000), Moldovanu and Sela (2006), Taylor (1995), both the set of contestants and the prize system, Che and Gale (2003), the structure of multi-stage contests, Gradstein (1998), Gradstein and Konrad (1999), Amegashie (2000), caps on political lobbying, Che and Gale (1998) and the contest success function, CSF, the function that relates the contestants' efforts to their winning probabilities, Che and Gale (1997), Nti (1997), (2004).

In the current study we focus on the design of logit CSF's that include two types of popular mechanisms: Tullock's type lotteries and all-pay-auctions. We show that in asymmetric contests with different prize valuations, the endogenously determined lottery always yields certain efforts that are larger than or equal to the expected efforts in an APA.

We first study fair non-discriminating logit CSF's, as in Alcalde and Dahm (2010) and Nti (2004), allowing control of the exponent determining the particular form of the logit CSF. In this context, Fang (2002) has shown that a fair simple lottery can be superior to an all-pay-auction and induce larger efforts, if the gap between the contestants' prize valuations is sufficiently large. Our main result considerably extends his finding. It establishes that the optimal fair (non-discriminating) lottery is always superior to the all-pay-auction (APA). That is, it yields larger efforts regardless of the gap between the contestants' stakes. We then extend the setting by allowing discrimination, that is, control of another parameter that determines the preferential treatment received by one of the contestants, as in Lien (1986), (1990), Clark and Riis (2000) and, more recently, Franke (2007), Epstein et al. (2011). Such 
discrimination is commonly observed in real political-economic contest environments, and, particularly, in the public sector (For a detailed discussion of the empirical relevance of discrimination and its control by contest designers see Epstein et al. (2011) and Franke et al. (2011)). By our second result, when discrimination is allowed, the optimal discriminating lottery cannot be dominated by the optimal discriminating APA because of the existence of a lottery that yields certain efforts that are equal to the expected efforts under the optimal APA.

Given our assumption of common knowledge of the contestants' prize valuations, the contest designer could resort to a mechanism that completely extracts the higher prize valuation. Focusing on contests with logit CSF's actually implies that we rule out such mechanisms. In other words, the contestants in our setting are in fact assumed to be protected from complete extraction of their surplus because they are ensured that in the contest equilibrium their participation is minimally effective; in equilibrium every contestant makes a positive effort with positive probability and has a positive probability of winning the contested prize. ${ }^{2}$ The focus on logit lotteries conforms therefore to a legal constraint that contests induce participation and that the designer cannot induce efforts that exceed, as we shall see, the average value of the contested prize.

It should be noted that the logit CSFs can be justified either axiomatically ${ }^{3}$ or on the grounds of common use in practice. In any event, they are the most widely studied functions in the contest literature. ${ }^{4}$ Despite their popularity, it must be admitted that it remains an open question whether some other CSFs, while still ensuring minimally effective participation of the contestants, can yield better expected results for the contest designer. In other words although we prove the superiority of Tullock-type lotteries over APAs, we cannot claim that they are the best minimally effective CSFs for the revenue-maximizing contest designer.

The remainder of the paper is laid out as follows. In Section 2, we present the model, the optimal contest design approach that allows discrimination and the two

\footnotetext{
${ }^{2}$ The existence of effective incentives of participation precludes the direct abolition of competition by exclusion of contestants or the indirect abolition of competition by application of a Tullock CSF that for some contestants is always unresponsive to their effort, as in Nti (2004).

${ }^{3}$ When discrimination between the contestants is permitted, we can use the axiomatic approach of Clark and Riis (1998). For axiomatization of a symmetric CSF see Skaperdas (1996). For a different axiomatic approach of both a discriminating or a symmetric CSF, see Jia (2008).

${ }^{4}$ Since the contested prize is assumed to be fixed, the possibility of applying a Tullock CSF with reimbursements, as in Cohen and Sela (2005) and Matros and Armanios (2009) is also disregarded.
} 
types of contest success functions, APAs and Tullock's logit lotteries. Section 3 contains the main result which establishes the inferiority of the APA relative to the endogenous lottery, when the contestants have different prize valuations. In Section 4 it is shown that the optimal discriminating lottery cannot be dominated by the optimal discriminating APA. Section 5 contains a brief summary and concluding remarks. All the proofs are relegated to an Appendix.

\section{Optimal contest design}

\section{a. The setting}

In the basic one-stage contest setting, there are two risk-neutral contestants, the high and low benefit contestants, 1 and 2. The prize valuations of the contestants are denoted by $n_{i}, n_{1}>n_{2}$ or $k=\frac{n_{1}}{n_{2}}>1$. Being chiefly concerned with the conditions under which the contest designer chooses an optimal contest, we assume that he has full knowledge of the contestants' prize valuations. Given the contestants' fixed prize valuations and the CSF, the function that specifies the contestants' winning probability given their efforts, $\operatorname{Pr}_{i}\left(x_{1}, x_{2}\right)$, the expected net payoff (surplus) of contestant $i$ is:

$$
E\left(u_{i}\right)=\operatorname{Pr}_{i}\left(x_{1}, x_{2}\right) n_{i}-x_{i},(i=1,2)
$$

where $x_{1}$ and $x_{2}$ denote the contestants' efforts. In the extended optimal contest design setting, the objective function of a third player, the designer of the contest, is:

$$
G=E\left(x_{1}+x_{2}\right)
$$

The contest designer is assumed to maximize his objective function (2) by setting the CSF, anticipating the Nash equilibrium efforts of the contestants that are obtained in the standard contest where the payoff functions of the contestants are given by (1) and the contest success function (the explicit form of $\operatorname{Pr}_{i}\left(x_{1}, x_{2}\right)$ ) is the one set by the designer. As already mentioned, we are interested in competitive environments that preclude abolition of competition by exclusion of contestants, as explained in the 
introduction. We therefore focus on the widely studied contests that are based on logit CSFs that include APAs and Tullock's lotteries. ${ }^{5}$

\section{b. All-Pay Auctions}

In our setting, certain winning means that the designer sets a CSF that leaves no residual winning uncertainty after the revelation of the contestants' efforts. In such a case, the certain winner is the contestant who makes the largest effective effort, where a unit of effort by one contestant is not necessarily equally effective as a unit of effort of his rival, as first suggested in the context of a bribery game by Lien (1986), (1990) and later on by Clark and Riis (2000). That is, the CSF for $\delta>0$ is an APA given by:

$$
p_{1}\left(x_{1}, x_{2}\right)=\left\{\begin{array}{lll}
1 & \text { if } & x_{1}>\delta x_{2} \\
0.5 & \text { if } & x_{1}=\delta x_{2} \\
0 & \text { if } & x_{1}<\delta x_{2}
\end{array}\right.
$$

and for $\delta=0, p_{1}\left(x_{1}, x_{2}\right)=1$, where the discrimination variable $\delta \geq 0$ is selected by the contest designer. By (3), a reduction in $\delta$ increases the bias in favor of the more motivated contestant 1 . Furthermore, $0 \leq \delta<1$ implies a bias in favor of contestant 1 . When $\delta=1$ the contest is fair, there is no bias. When $\delta>1$ the bias is in favor of contestant 2 .

\section{c. The logit lotteries}

When winning is uncertain, the designer sets a CSF that leaves some residual winning uncertainty after the revelation of the contestants' efforts. In such a case, in equilibrium every contestant has some positive winning probability. Sufficiently large investment of effort can secure a high probability of winning, but not certain winning.

Our optimality and neutrality results are confined to the well studied logit Tullock-type lotteries. For $\delta>0$, these lotteries are given by: ${ }^{6}$

\footnotetext{
${ }^{5}$ In Epstein et al. (2011), when the weight assigned to the expected welfare of the contestants is sufficiently high, in equilibrium there is no contest (and so no efforts are made) and the winner is the contestant with the higher valuation. In contrast, in our model, such equilibrium cannot emerge since the weight assigned to the expected welfare of the contestants is zero. Therefore, any equilibrium is an interior one: there is real competition and "meaningful" winning (each contestant makes an effort with a positive winning probability).
} 


$$
p_{1}\left(x_{1}, x_{2}\right)=\frac{x_{1}^{\alpha}}{x_{1}^{\alpha}+\left(\delta x_{2}\right)^{\alpha}}
$$

$0<\alpha<\infty$ and for $\delta=0, p_{1}\left(x_{1}, x_{2}\right)=1$, where $\alpha$ and $\delta$ are selected by the contest designer. The interpretation of $\delta$ is as in sub-section (b).

\section{Fair contests}

As in Alcalde and Dahm (2010) and Nti (2004), consider environments where the designer cannot or does not want to discriminate between the contestants, $\delta=1$. That is, he cannot grant one contestant an advantage over his rival. This is the standard type of fair (unbiased) contest studied in the literature, see Konrad (2009).

\section{a. The unbiased APA}

In equilibrium of the unbiased APA, Hillman and Riley (1989), Konrad (2009), the expected efforts are $x_{1}^{*}=0.5 n_{2}$ and $x_{2}^{*}=\frac{n_{2}^{2}}{2 n_{1}}$. In turn, the expected net payoff of the player with the lower prize valuations is zero, namely, when $k>1$, only the player with the higher prize valuations enjoys some surplus. The expected net payoff of the player with the higher prize valuations is equal to $E\left(u_{1}^{*}\right)=\left(n_{1}-n_{2}\right)$. In equilibrium, the value of the designer's objective function (the expected aggregate efforts of the contestants in the mixed-strategy equilibrium) is equal to $G_{A}=\frac{n_{2}\left(n_{1}+n_{2}\right)}{2 n_{1}}$.

\section{b. The optimal unbiased lottery}

With asymmetric prize valuations, $k>1$, and $\alpha=1$, it is known that in equilibrium $G_{L}=\frac{n_{1} n_{2}}{n_{1}+n_{2}}$ is larger than $G_{A}$, provided that the gap between the contestants' stakes is sufficiently large, that is, $k>1+\sqrt{2}$ (see Fang (2002, section 5.2)). Our first result

\footnotetext{
${ }^{6}$ As is well known, see Konrad (2009) and references therein, when $0<\alpha \leq 2$ the contest has a purestrategy equilibrium. Since $p_{1}\left(x_{1}, x_{2}\right)=\frac{x_{1}^{\alpha}}{x_{1}^{\alpha}+\left(\delta x_{2}\right)^{\alpha}}=\frac{1}{1+\left(\delta x_{2} / x_{1}\right)^{\alpha}}$, one can easily see that for $\alpha=\infty$ the logit lottery takes the form (3). The form in (4) is slightly different from the form of the logit lottery in Epstein et al. (2011) because in the present study, as will become clear in the sequel, it is important to make a meaningful comparison between the degree of discrimination under the two types of CSFs. Such comparison requires that discrimination is defined in a similar way in the two cases.
} 
considerably strengthens this finding by establishing that in a fair contest $(\delta=1)$, if $k>1$, then a designer who can select the exponent $\alpha$, always prefers a logit lottery because it yields larger efforts relative to the APA, even when the sufficient condition $k>1+\sqrt{2}$ is not satisfied. In fact, the exponent of the preferred lottery satisfies $0<\alpha<2$, which means that the corresponding contest game has a unique purestrategy equilibrium (see footnote 6 ).

\section{Proposition 1:}

If discrimination is not feasible, $k>1$ and the designer can select the exponent of the lottery, then there exists a value in the range $0<\alpha<2$ that yields certain contestants' efforts that are larger than the expected efforts obtained under the APA.

(For a proof, see Appendix A).

This result implies that, in a fair contest, if $k>1$, then a Tullock-type lottery is always preferred to the APA by a risk neutral or a risk averse designer. Alcalde and Dahm (2010) have shown that for any $\alpha \geq 2$ there exists an equilibrium in mixed strategies that is equivalent to the equilibrium of the APA. However, so far a characterization of the complete set of mixed-strategy equilibria is not available. Since we show that there exists $\alpha, 0<\alpha<2$, that yields efforts that are larger than those obtained under the APA, it is clear that this conclusion remains valid when the parameter $\alpha$ has to satisfy the requirement $0<\alpha<\infty$.

Let us explain the economic intuition behind the result, namely, why $k>1$ gives rise to a pure-strategy equilibrium corresponding to $0<\alpha(k)<2$ which is preferred to the mixed-strategy equilibrium obtained under the APA (the logit CSF where $\alpha=\infty$ ).

For $k>1$, a designer setting an optimal $\alpha$ for a pure-strategy equilibrium must choose an exponent $\alpha$ which is smaller than 2. Furthermore, in a pure-strategy equilibrium the designer may choose an exponent that is smaller than that $\alpha$ which causes contestant 2's utility to be equal to zero. In other words, in equilibrium contestant 2's utility can be positive. This has been shown by Nti (2004) for a sufficiently large value of $k$ (see Section 4 in his paper). However, for lower values of 
$k$, but still $k>1, \alpha$ reduces contestant 2's utility to zero. ${ }^{7}$ In any case, as explained above, for $k>1$ the optimal $\alpha$ for a pure-strategy equilibrium is smaller than 2 , $0<\alpha(k)<2$.

Under the APA where $\alpha=\infty$, the contest equilibrium is in mixed strategies, the total expected efforts are equal to $G_{L}=\frac{n_{2}\left(n_{1}+n_{2}\right)}{2 n_{1}}$ and the surplus of contestant 2 is completely eliminated. It remains to explain why the designer prefers the optimal pure-strategy equilibrium to the mixed-strategy equilibrium. Notice that in the move from equilibrium in pure strategies to equilibrium in mixed strategies $\alpha$ is increased, however, $x_{1}^{*} / x_{2}^{*}=k^{8}$ The increase in $\alpha$ increases the winning probability of contestant 1 and reduces the winning probability of contestant 2. However, contestant 1 is induced to reduce his efforts in the mixed-strategy equilibrium corresponding to the larger $\alpha$ because this further increases his expected utility. Such reduction is possible because contestant 2 whose utility is reduced or remains equal to zero in the mixed-strategy equilibrium is also induced to reduce his effort. ${ }^{9}$

Che and Gale (1997) point out that intuition suggests that a society with contest designers who are receptive to rent seeking (a large exponent $\alpha$ ) would induce greater rent-seeking expenditures than other societies, all else equal. Our result establishes that this intuition is not valid when we move from the range $0<\alpha \leq 2$ to $\alpha=\infty$. In particular, when $\delta=1$ and $k>1$, the parameter $\alpha$ in the logit CSF on which we focus, that yields the largest efforts is not $\alpha=\infty$, since there is some $\alpha$ which is smaller than 2 that yields larger efforts.

\section{Unconstrained contests}

In a Nash equilibrium of the contest, every contestant optimally determines his investment, given the parameters of the contest success function. In the unconstrained

\footnotetext{
${ }^{7}$ The critical $k$ is $k=3.509$.

${ }^{8}$ By substituting $\delta=1$ in equation (3.B) in Appendix B, we get that the contestants' efforts in a purestrategy equilibrium are equal to $x_{1 p}^{*}=\frac{\alpha n_{1} k^{\alpha}}{\left(k^{\alpha}+1\right)^{2}}$ and $x_{2 p}^{*}=\frac{\alpha n_{2} k^{\alpha}}{\left(k^{\alpha}+1\right)^{2}}$. Under the APA their expected efforts are $x_{1 m}^{*}=0.5 n_{2}$ and $x_{2 m}^{*}=\frac{n_{2}^{2}}{2 n_{1}}$. Hence, $\frac{x_{1 p}^{*}}{x_{2 p}^{*}}=\frac{x_{1 m}^{*}}{x_{2 m}^{*}}=k$.

${ }^{9}$ Recall that in the pure-strategy equilibrium the utility of contestant 2 can be positive if $k$ is sufficiently large (see footnote 7).
} 
environment that allows discrimination, anticipating the investments of the contestants, the designer optimally determines the parameters of the contest's success functions. When considering the APA the designer controls the degree of discrimination $\delta$. When considering the logit lottery he determines both $\delta$ and the exponent $\alpha$.

Most of the literature studying Tullock's lotteries and the APA disregarded deliberate discrimination between the contestants and control of the exponent $\alpha$. However, in the context of an APA, Lien (1986), (1990) and Clark and Riis (2000) studied a bribery game in which an official (designer) exercises discrimination in a multiplicative form. Nti (2004) examined the effect of the exponent $\alpha$ on the contestants' efforts in Tullock' lotteries disregarding discrimination between the contestants and focusing on pure-strategy equilibria. He thus initiated the study of optimal contest design by control of the exponent $\alpha$ for Tullock's CSFs. Recently, Epstein et al. (2011) presented a complete analysis of the designer's effect on the contestants' efforts by control of the degree of discrimination both for the APA and the logit lotteries, assuming that in the lotteries' case the exponent $\alpha$ is given and restricted to the range $0<\alpha \leq 1$. They have thus re-shifted the emphasis in the study of optimal contest design to the control of discrimination. The current section combines the two approaches allowing the designer to control both the exponent $\alpha$ and the degree of discrimination between the contestants. In addition, it generalizes the analysis by allowing any value of the exponent $\alpha$ in the logit CSFs that gives rise to a Tullock-type lottery associated with a pure-strategy or a mixed-strategy equilibrium, $0<\alpha<\infty$, or to an APA that is associated with a mixed-strategy equilibria where $\alpha=\infty$. $^{10}$

\section{a. The optimal APA}

Under the APA, the designer of the contest maximizes his objective function, (2), by determining the optimal value of $\delta$. The optimal $\delta$ is equal to $k$ (for a proof, see Epstein et al. (2011), Proposition 1, assuming that no weight is assigned to the expected welfare of the contestants). This optimal bias accomplishes the designer's attempt to maximize the extent of competition between the contestants. In fact, such

\footnotetext{
${ }^{10}$ Note that under the logit CSF where $0<\alpha \leq 2$ the exerted efforts are certain whereas under the APA the meaning of efforts is expected efforts.
} 
bias eliminates the advantage of contestant 1, creates actual equality between the competitors and completely eliminates their surplus. The corresponding value of the designer's objective function (the expected aggregate efforts of the contestants in the mixed-strategy equilibrium of the contest) is $G_{A}=0.5\left(n_{1}+n_{2}\right)$. Thus, in equilibrium, the expected payoff of the designer is equal to the average prize valuation.

\section{b. The optimal lottery}

Under the logit contest success function, the designer determines the optimal level of $\alpha, 0<\alpha<\infty$, and $\delta, \delta \geq 0$. Let us partition the range of the parameter $\alpha$ into $0<\alpha \leq 2$ and $2<\alpha<\infty$. For $0<\alpha \leq 2$, where a unique pure-strategy equilibrium exists, the optimal values of $\delta$ and $\alpha$ are equal to $\delta^{*}=k$ and $\alpha^{*}=2$ (for a proof, see Appendix B. This proof has to take into account constraints that are not automatically satisfied as in Epstein et al. (2011) where $0<\alpha \leq 1$. For further more specific clarification of this point see footnote $16 .{ }^{11}$ The corresponding value of the designer's objective function (the certain aggregate efforts of the contestants in the pure-strategy equilibrium of the contest) is $G_{L}=0.5\left(n_{1}+n_{2}\right)=G_{A} \cdot{ }^{12}$ We therefore obtain:

\section{Proposition 2:}

If the contest designer can select both the degree of discrimination $\delta, \delta \geq 0$, and the exponent $\alpha$, then the contestants' expected efforts of the optimal lottery are larger than or equal to those in the mixed-strategy equilibrium of the optimal APA.

\footnotetext{
${ }^{11}$ We suggest the following intuition regarding the equilibrium (in pure strategies) outcome and its sensitivity to $\alpha \quad(0<\alpha \leq 2)$. The designer tends to support the contestant with the lower prize valuation $\left(\delta^{*}=k\right)$ to attain complete "balance" between the contestants' wining probabilities (ensure that $p_{i}=0.5$ ), for any given $\alpha, 0<\alpha \leq 2$. An increase in $\alpha$ induces the contestants to increase their effort at the same rate in order to increase their winning probability. Since at the same time the designer favorably discriminates the contestant with the lower prize valuation, the equilibrium winning probability is unchanged, $p_{i}=0.5$. But by raising $\alpha$ the designer increases the aggregate efforts, and in turn his payoff. The designer therefore prefers the highest possible $\alpha, \alpha=2$, that enables him to extract the maximal possible surplus from the contestants which reduces their net payoff to zero.

${ }^{12}$ Note that this result has the flavor of the neutrality result of Alcalde and Dahm (2010). However, in our setting of optimal contest design, the contestants' maximal efforts are larger than those obtained in the symmetric setting of Alcalde and Dahm (2010). This is due, first, to the allowed discrimination between the contestants and, second, to the allowed control of the designer over the desirable value of the exponent $\alpha$.
} 
The combined effect of optimal discrimination $\delta=k$ and optimal selection of the exponent $\alpha$ in the logit CSF

$$
p_{1}\left(x_{1}, x_{2}\right)=\frac{x_{1}^{\alpha}}{x_{1}^{\alpha}+\left(\delta x_{2}\right)^{\alpha}}=\frac{1}{1+\left(\delta x_{2} / x_{1}\right)^{\alpha}}
$$

that gives rise to a pure-strategy equilibrium when $0<\alpha \leq 2$, results in equal (expected) efforts and elimination of the surplus of both of the contestants. This result implies that the optimal logit lottery (that need not satisfy the constraint $0<\alpha \leq 2$ ) cannot be dominated by the APA.

Proposition 2 establishes that the intuition mentioned above that a larger exponent $\alpha$ would induce greater rent-seeking expenditures is, again, not valid. Under optimal discrimination, even the use of an optimal APA by designers who are maximally receptive to the contestants' efforts, would not induce greater efforts than those obtained by designers who are less receptive to the contestants' efforts, $\alpha^{*}=2$, allowing random winning. Recall that in both cases bids are optimally discriminated, the optimal degree of discrimination being equal to $k$. Nevertheless, the valid part of the above intuition is that a larger exponent $\alpha$ indeed induces greater efforts under the logit lottery provided that the exponent $\alpha$ gives rise to a pure-strategy equilibrium.

\section{Conclusion}

\section{a. Brief summary of the results}

Our two results establish that, under common knowledge of the two asymmetric contestants' prize valuations, a fair non-discriminating Tullock-type lottery associated with a pure-strategy equilibrium is always superior to an all-pay-auction. That is, a lottery with an appropriately chosen exponent always yields higher expected revenues for the contest designer than an APA. When discrimination between the contestants is allowed, there exists a lottery which is equivalent to the optimal APA. Hence, the endogenously determined optimal lottery cannot be dominated by the optimal APA.

\section{b. Extraction of the contestants' surplus and the designer's payoff}

In the unconstrained environment that allows discrimination, the designer always captures all the surplus of the two contestants. In the constrained fair environment, this is not the case although under the APA the designer always captures the surplus 
of contestant 2, the player with the lower prize valuation. The difference between the two competitive environments is the extent of the contestants' incentives to make efforts. This hinges on the possibility of discrimination between the contestants. The possibility of discrimination increases the intensity of competition enabling the designer to increase his payoff.

\section{c. The shadow price of the competitiveness constraint}

The competitiveness constraint means that we deal with interior contest equilibria such that the ability of the contest designer to induce efforts is limited to the average value of the contested prize. Without this constraint, the designer could yield a total effort of $n_{1}$ by excluding the rivals of the contestant with the maximal valuation of the contested prize and then exploiting his political power or bargaining advantage to extract (almost) all his surplus, as in Nti (2004). We should point out that several different mechanisms can be used to implement the optimal design. For example, we could use an auction mechanism where the prize is awarded to the highest bidder but the contest designer has a reserve price equal to $n_{1}$ (see Glazer, 1993) or, alternatively, use a first-price APA with a reservation price of $n_{1}$ (see Hillman and Riley, 1989). The CSFs on which we focus do conform to the competitive environment and the maximal efforts are equal to $0.5\left(n_{1}+n_{2}\right)$. This result is consistent with the constraint on the ability of the designer to induce efforts being binding. The shadow price of the competitiveness constraint is therefore equal to $n_{1}-0.5\left(n_{1}+n_{2}\right)=0.5\left(n_{1}-n_{2}\right)$. This is then the price of competition for the designer.

\section{d. The shadow price of the equalitarian constraint}

Equalitarianism results in reduced payoff for the designer relative to the unconstrained environment when $k>1$. In this case the shadow price of this constraint is positive, the exact value depending on the gap between the contestants' prize valuations that gives a Tullock's lottery a clear-cut advantage over the APA, as implied by Proposition 1 . This may certainly support an ideology protecting the equalitarian 'welfare state'. Simply, in our setting, such equalitarianism limits the ability of the political-economic entrepreneur to extract resources from the contestants. 


\section{e. Generalization to n-player contests}

A potential interesting extension of our study is the analysis of the multiple-player case. Results for the all-pay auction should be robust with respect to the number of players because only two players will actively participate in equilibrium. The case of optimal discrimination by control of the bias scheme has been recently analyzed in Franke et al. (2011) assuming the simple lottery case where $\alpha=1$; the contestants' winning probabilities are equal to their relative exerted efforts. Even the analysis of this relatively simple case is rather complex. Its extension to our more general setting of Tullock lotteries, where $0<\alpha \leq 2$, seems an especially demanding challenge.

\section{References}

Alcalde, J. and Dahm, M., (2010), "Rent Seeking and Rent Dissipation: A Neutrality Result", Journal of Public Economics, 94, 1-7.,

Amegashie, J.A., (2000), "Some Results on Rent-Seeking Contests with Shortlisting," Public Choice, 105 (3-4), 245-253.

Baye, M.R., Kovenock, D. and de Vries, C., (1993), "Rigging the Lobbying Process: An Application of the All-Pay Auction", American Economic Review, 83, 289294.

Che, Y.K and Gale, I., (1997), "Rent Dissipation When Rent Seekers Are Budget Constrained", Public Choice, 92, 109-126.

Che, Y.K and Gale, I., (1998), "Caps on Political Lobbying", American Economic Review, 88, 643-651.

Che, Y.K and Gale, I., (2003), "Optimal Design of Research Contests", American Economic Review, 93(3), 646-671.

Clark, D.J., Riis, C., (1998), Contest success functions: an extension, Economic Theory, 11, 201-204.

Clark, D.J., Riis, C., (2000), “Allocation Efficiency in a Competitive Bribery Game”, Journal of Economic Behavior and Organization, 42, 109-124.

Cohen, C. and Sela, A., (2005), Manipulations in Contests, Economics Letters, 86, 135-139.

Congleton, R.D., Hillman A.L. and Konrad K.A., (2008), editors, The Theory of Rent Seeking: Forty Years of Research, Springer, Heidelberg and Berlin.

Epstein G.S., Mealem Y. and Nitzan S., (2011), "Political Culture and Discrimination in Contests", Journal of Public Economics, 95(1-2), 88-93. 
Epstein G.S. and Nitzan S., (2002), "Endogenous Public Policy, Politicization and Welfare", Journal of Public Economic Theory, 4(4), 661-677.

Epstein, G.S. and Nitzan, S., (2006a), "Effort and Performance in Public-Policy Contests”, Journal of Public Economic Theory, 8(2), 265-282.

Epstein, G.S. and Nitzan, S., (2006b), "The Politics of Randomness”, Social Choice and Welfare, 27(2), 423-433.

Epstein, G.S. and Nitzan, S., (2007), Endogenous Public Policy and Contests. Springer.

Fang, H., (2002), Lottery versus All-Pay Auction Models of Lobbying", Public Choice, 112, 351-371.

Franke, J., (2007), "Does Affirmative Action Reduce Effort Incentives? A Contest Game Analysis", Ruhr Economic Papers \#185, TU Dortmund.

Franke J. , Kanzow C. Leininger W. and Schwartz A. , (2011), “Effort Maximization in Asymmetric Contest Games with Heterogeneous Contestants”, Economic Theory, forthcoming.

Glazer, A. and Hassin, R., (1988), "Optimal Contests", Economic Inquiry, 26(1), 133143.

Glazer, A., (1993), "On the Incentives to Establish and Play Political Rent-Seeking Games", Public Choice, 75, 139-148.

Gradstein, M., (1998), “Optimal Contest Design: Volume and Timing of Rent Seeking in Contests”, European Journal of Political Economy, 14(4), 575-585.

Gradstein, M. and Konrad, K., (1999), “Orchestrating Rent Seeking Contests”, Economic Journal, 109, 536-545.

Hillman, A.L. and Riley, J.G., (1989), "Politically Contestable Rents and Transfers”, Economics and Politics, 1, 17-39.

Jia, H., (2008), “A Stochastic Derivation of the Ratio Form of Contest Success Functions”, Public Choice, 135, 125-130.

Konrad, K., (2009), Strategy and Dynamics in Contests (London School of Economic Perspectives in Economic Analysis), Oxford University Press, USA.

Lien, D., (1986), “A Note on Competitive Bribery Games”, Economics Letters, 22, 337341.

Lien, D., (1990), “Corruption and Allocation Efficiency”, Journal of Development Economics, 33, 153-164. 
Matros, A. and Armanios, D., (2009), "Tullock’s contest with reimbursements", Public Choice, 141, 49-63.

Moldovanu, M. and Sela, A., (2006), "Contest Architecture", Journal of Economic Theory, 126(1), 70-96

Nti, K.O., (1997), "Comparative Statics of Contests and Rent-Seeking Games", International Economic Review, 38(1), 43-59.

Nti, K.O., (2004), "Maximum Efforts in Contests with Asymmetric Valuations", European Journal of Political Economy, 20(4), 1059-1066.

Runkel, M., (2006), "Optimal Contest Design, Closeness and the Contest Success Function", Public Choice, 129, 217-231.

Singh, N. and Wittman, D., (1998), "Contest Design and the Objective of the Contest Designer: Sales, Promotion, Sports Events and Patent Races", in Baye's (ed.) Advances in Microeconomics, Vol. 7, JAI Press, 139-167.

Skaperdas, S., (1996), "Contest success functions". Economic Theory, 7, 283-290.

Taylor, C.R., (1995), "Digging for Golden Carrots: An Analysis of Research Tournaments", American Economic Review, 85(4), 872-90.

Tullock, G., (1980), Efficient Rent-Seeking. In: Buchanan J.M, Tollison R.D, Tullock G., (ed) Toward a Theory of the Rent-Seeking Society, College Station, TX, Texas A. and M., University Press, 97-112 


\section{Appendix A: Proof of Proposition 1}

When discrimination is not allowed, $\delta=1$, and the exponent $\alpha$ is chosen optimally taking the form $\alpha(k)$, by $\mathrm{Nti}$ (2004), in the range $0<\alpha \leq 2$ the pure-strategy equilibrium results in ${ }^{13}$

$$
G_{L}^{p s}=\frac{\alpha k^{\alpha}\left(n_{1}+n_{2}\right)}{\left(k^{\alpha}+1\right)^{2}}
$$

and under the APA, where $\alpha=\infty$, the mixed-strategy equilibrium results in

$$
G_{A}=\frac{n_{2}\left(n_{1}+n_{2}\right)}{2 n_{1}}=\frac{n_{1}+n_{2}}{2 k}
$$

Denote by $\bar{\alpha}$, which is a function of the parameter $k$, the solution of

$$
(\alpha-1) k^{\alpha}=1
$$

Under such equality the expected utility of contestant 2, the contestant with the low value of the prize, is equal to zero. Equality (1.A) implies that $\bar{\alpha}>1, \bar{\alpha} k^{\bar{\alpha}}=k^{\bar{\alpha}}+1$, $\frac{\partial \bar{\alpha}}{\partial k}<0, \bar{\alpha}(k=1)=2$ and $(k \rightarrow \infty) \Rightarrow(\bar{\alpha} \rightarrow 1)$, Hence, for every $k>1,1<\bar{\alpha}<2$.

Nti (2004, Theorem 3) has shown that for $k \leq 3.509$, the solution (in implicit form) of equation (1.A), $\bar{\alpha}$, is the optimal solution that maximizes $G_{L}^{p s}$. Otherwise the solution differs from $\bar{\alpha}$. This means that

$$
\operatorname{Max}_{L}^{p s} \geq \frac{\bar{\alpha} k^{\bar{\alpha}}\left(n_{1}+n_{2}\right)}{\left(k^{\bar{\alpha}}+1\right)^{2}}=\frac{\bar{\alpha} k^{\bar{\alpha}}\left(n_{1}+n_{2}\right)}{\left(\bar{\alpha} k^{\bar{\alpha}}\right)^{2}}=\frac{n_{1}+n_{2}}{\bar{\alpha} k^{\bar{\alpha}}}
$$

Therefore, when $\frac{n_{1}+n_{2}}{\bar{\alpha} k^{\bar{\alpha}}}>G_{A}$ we get that $\operatorname{Max}_{L}^{p s}>G_{A}$. That is,

$$
\frac{n_{1}+n_{2}}{\bar{\alpha} k^{\bar{\alpha}}}>\frac{n_{1}+n_{2}}{2 k}
$$

or

$$
2 k^{1-\bar{\alpha}}>\bar{\alpha}
$$

By (1.A), $k=(\bar{\alpha}-1)^{-\frac{1}{\bar{\alpha}}}$. Substituting $k$ in the latter inequality we get:

$$
2(\bar{\alpha}-1)^{\frac{\bar{\alpha}-1}{\bar{\alpha}}}>\bar{\alpha}
$$

\footnotetext{
${ }^{13}$ Notice that Nti defines $k$ as the inverse of our $k$, that is, in his case $k=n_{2} / n_{1}$. Consequently, his result is presented with the appropriate modification.
} 
or $(\bar{\alpha}-1)^{\frac{\bar{\alpha}-1}{\bar{\alpha}}}>0.5 \bar{\alpha}$ or $(\bar{\alpha}-1)^{\bar{\alpha}-1}>(0.5 \bar{\alpha})^{\bar{\alpha}}$ or:

$$
(\bar{\alpha}-1)^{\bar{\alpha}-1}-(0.5 \bar{\alpha})^{\bar{\alpha}}>0
$$

Notice that if inequality (2.A) holds for $1<\bar{\alpha}<2$, then it is satisfied for every $k>1 .^{14}$

The reason is that an increase in $k$ reduces $\bar{\alpha}$ and for $k=1, \bar{\alpha}=2$ whereas for $k \rightarrow \infty, \bar{\alpha}$ converges to 1 .

Let $f(\bar{\alpha})=(\bar{\alpha}-1)^{\bar{\alpha}-1}$ and $g(\bar{\alpha})=(0.5 \bar{\alpha})^{\bar{\alpha}}$. To prove inequality (2.A), we have to show that for $1<\bar{\alpha}<2, f(\bar{\alpha})>g(\bar{\alpha}) .{ }^{15}$

Consider first the two functions $f$ and $g$ at $1<\bar{\alpha} \leq 2$. It can be verified that $\varliminf_{\bar{\alpha} \rightarrow 1} f(\bar{\alpha})=1, f(2)=1$ and $\frac{d f(\bar{\alpha})}{d \bar{\alpha}}=(\bar{\alpha}-1)^{\bar{\alpha}-1}[1+\ln (\bar{\alpha}-1)]$. Therefore, for $1<\bar{\alpha} \leq 2$,

$f$ is minimized at $\bar{\alpha}=1+e^{-1}$, where $\min f(\bar{\alpha})=\left(e^{-1}\right)^{e^{-1}}=0.6922$. In contrast, for $1<\bar{\alpha} \leq 2$, we get that $\frac{d g(\bar{\alpha})}{d \bar{\alpha}}=(0.5 \bar{\alpha})^{\bar{\alpha}}[1+\ln (0.5 \bar{\alpha})]>0$. That is, the function $g$ is increasing in the domain $1<\bar{\alpha} \leq 2$.

Partitioning this domain, $1<\bar{\alpha} \leq 2$, into two subsets: $1<\bar{\alpha} \leq 1+e^{-1}$ and $1+e^{-1}<\bar{\alpha} \leq 2$, let us show that in each of these sub-domains inequality (2.A) is satisfied.

Consider first the sub-domain $1<\bar{\alpha} \leq 1+e^{-1}$. Since at $\bar{\alpha}=1+e^{-1}$, $g\left(1+e^{-1}\right)=0.5947<0.6922=\min f(\bar{\alpha})$, and since, as noted above, $g$ is increasing in the domain $1<\bar{\alpha} \leq 2$, we get that for $1<\bar{\alpha} \leq 1+e^{-1}, f(\bar{\alpha})>g(\bar{\alpha})$.

To complete the proof, let us show that the latter inequality is also satisfied for $1+e^{-1}<\bar{\alpha}<2$. In this subset of the domain of $f$ and $g, 0.5 \bar{\alpha}>\bar{\alpha}-1>e^{-1}$ or $\ln (0.5 \bar{\alpha})>\ln (\bar{\alpha}-1)>\ln e^{-1} \quad$ or $\quad \ln (0.5 \bar{\alpha})>\ln (\bar{\alpha}-1)>-1 \quad$ or $1+\ln (0.5 \bar{\alpha})>1+\ln (\bar{\alpha}-1)>0 \quad$ or $\quad \frac{1+\ln (0.5 \bar{\alpha})}{1+\ln (\bar{\alpha}-1)}>1$. Note that when $\bar{\alpha}=2$,

\footnotetext{
${ }^{14}$ When $k=1, \bar{\alpha}=2$ and we get that $\operatorname{Max} G_{L}^{p s}=G_{A}=0.5\left(n_{1}+n_{2}\right)=n_{1}$.

${ }^{15}$ We are indebted to Arkadi Koziashvili for his help in establishing this part of the proof.
} 
$\frac{1+\ln (0.5 \bar{\alpha})}{1+\ln (\bar{\alpha}-1)}=1$. To sum up, when $1+e^{-1}<\bar{\alpha}<2$, we get that $\frac{1+\ln (0.5 \bar{\alpha})}{1+\ln (\bar{\alpha}-1)}>1$ and when $\bar{\alpha}=2, \frac{1+\ln (0.5 \bar{\alpha})}{1+\ln (\bar{\alpha}-1)}=1$.

Let $h(\bar{\alpha})=f(\bar{\alpha})-g(\bar{\alpha})$. This function is continuous and differentiable in the interval $1+e^{-1} \leq \bar{\alpha} \leq 2$ and $\frac{d h(\bar{\alpha})}{d \bar{\alpha}}=f(\bar{\alpha})[1+\ln (\bar{\alpha}-1)]-g(\bar{\alpha})[1+\ln (0.5 \bar{\alpha})]$. When the function $\quad h(\bar{\alpha}) \quad$ has $\quad$ an $\quad$ extremum, $\quad \frac{d h(\bar{\alpha})}{d \bar{\alpha}}=0 \quad$ or $f(\bar{\alpha})[1+\ln (\bar{\alpha}-1)]-g(\bar{\alpha})[1+\ln (0.5 \bar{\alpha})]=0$ or:

$$
\frac{f(\bar{\alpha})}{g(\bar{\alpha})}=\frac{1+\ln (0.5 \bar{\alpha})}{1+\ln (\bar{\alpha}-1)}
$$

We therefore get that:

1. The latter equality is satisfied for $\bar{\alpha}=2$ which means that this value is an extremum value. In addition, for this extremum value, $f(\bar{\alpha})=g(\bar{\alpha})$ or $h(\bar{\alpha})=0$.

2. As noted above, when $1+e^{-1}<\bar{\alpha}<2$, we get that $\frac{1+\ln (0.5 \bar{\alpha})}{1+\ln (\bar{\alpha}-1)}>1$ and, in addition, by (3.A), $\frac{f(\bar{\alpha})}{g(\bar{\alpha})}=\frac{1+\ln (0.5 \bar{\alpha})}{1+\ln (\bar{\alpha}-1)}$. Therefore, every extremum value in this sub-domain, $\quad 1+e^{-1}<\bar{\alpha}<2$, satisfies the inequality $\frac{f(\bar{\alpha})}{g(\bar{\alpha})}=\frac{1+\ln (0.5 \bar{\alpha})}{1+\ln (\bar{\alpha}-1)}>1$ or $\frac{f(\bar{\alpha})}{g(\bar{\alpha})}>1$. Hence, every extremum value in this sub-domain satisfies $f(\bar{\alpha})>g(\bar{\alpha})$ or $h(\bar{\alpha})>0$.

3. Also note that $h\left(\bar{\alpha}=1+e^{-1}\right)=0.0975$.

By $1-3$, we get that in the interval $1+e^{-1} \leq \bar{\alpha} \leq 2$, the point $(\bar{\alpha}, h(\bar{\alpha}))=(2,0)$ is an absolute minimum point. In other words, in the interval $1+e^{-1}<\bar{\alpha}<2, h(\bar{\alpha})>0$ or $f(\bar{\alpha})>g(\bar{\alpha})$. 


\section{Appendix B: The optimal logit CSF under discrimination}

The designer controls the parameters $\delta$ and $\alpha$. For $0<\alpha \leq 2,{ }^{16}$ which ensures the existence of an interior equilibrium, see Konrad (2009), and for $\delta>0$, the expected payoff of the contestants are:

$$
E\left(u_{1}\right)=\frac{n_{1} x_{1}^{\alpha}}{x_{1}^{\alpha}+\left(\delta x_{2}\right)^{\alpha}}-x_{1} \text { and } E\left(u_{2}\right)=\frac{n_{2}\left(\delta x_{2}\right)^{\alpha}}{x_{1}^{\alpha}+\left(\delta x_{2}\right)^{\alpha}}-x_{2}
$$

The first order conditions are:

$$
\frac{\partial E\left(u_{1}\right)}{\partial x_{1}}=\frac{\alpha x_{1}^{\alpha-1} n_{1}\left(\delta x_{2}\right)^{\alpha}}{\left[x_{1}^{\alpha}+\left(\delta x_{2}\right)^{\alpha}\right]^{2}}-1=0 \text { and } \frac{\partial E\left(u_{2}\right)}{\partial x_{2}}=\frac{\alpha \delta^{\alpha} x_{2}^{\alpha-1} n_{2} x_{1}^{\alpha}}{\left[x_{1}^{\alpha}+\left(\delta x_{2}\right)^{\alpha}\right]^{2}}-1=0
$$

and, after rearranging, we get that in equilibrium:

$$
\begin{gathered}
x_{1}^{*}=\frac{\alpha n_{1}(\delta k)^{\alpha}}{\left(k^{\alpha}+\delta^{\alpha}\right)^{2}}, x_{2}^{*}=\frac{\alpha n_{2}(\delta k)^{\alpha}}{\left(k^{\alpha}+\delta^{\alpha}\right)^{2}} \text { and } x_{1}^{*}+x_{2}^{*}=\frac{\alpha(\delta k)^{\alpha}\left(n_{1}+n_{2}\right)}{\left(k^{\alpha}+\delta^{\alpha}\right)^{2}} \\
p_{1}=\frac{k^{\alpha}}{k^{\alpha}+\delta^{\alpha}} \text { and } p_{2}=\frac{\delta^{\alpha}}{k^{\alpha}+\delta^{\alpha}} \\
E\left(u_{1}^{*}\right)=\frac{n_{1} k^{\alpha}\left[(1-\alpha) \delta^{\alpha}+k^{\alpha}\right]}{\left(k^{\alpha}+\delta^{\alpha}\right)^{2}} \text { and } E\left(u_{2}^{*}\right)=\frac{n_{2} \delta^{\alpha}\left[(1-\alpha) k^{\alpha}+\delta^{\alpha}\right]}{\left(k^{\alpha}+\delta^{\alpha}\right)^{2}}
\end{gathered}
$$

The second order equilibrium conditions (SOC) are:

$$
\begin{aligned}
& \frac{\partial^{2} E\left(u_{1}\right)}{\partial x_{1}^{2}}=\frac{\alpha n_{1}\left(\delta x_{2}\right)^{\alpha} x_{1}^{\alpha-2}\left\{(\alpha-1)\left(\delta x_{2}\right)^{\alpha}-(\alpha+1) x_{1}^{\alpha}\right\}}{\left[x_{1}^{\alpha}+\left(\delta x_{2}\right)^{\alpha}\right]^{3}} \leq 0 \\
& \frac{\partial^{2} E\left(u_{2}\right)}{\partial x_{2}^{2}}=\frac{\alpha n_{2} \delta^{\alpha} x_{1}^{\alpha} x_{2}^{\alpha-2}\left\{(\alpha-1) x_{1}^{\alpha}-(\alpha+1)\left(\delta x_{2}\right)^{\alpha}\right\}}{\left[x_{1}^{\alpha}+\left(\delta x_{2}\right)^{\alpha}\right]^{3}} \leq 0
\end{aligned}
$$

In equilibrium we obtain that $\frac{x_{1}^{*}}{x_{2}^{*}}=k$, therefore the SOC can be written as:

$$
(1-\alpha) \delta^{\alpha}+(\alpha+1) k^{\alpha} \geq 0 \text { and }(1-\alpha) k^{\alpha}+(\alpha+1) \delta^{\alpha} \geq 0
$$

Also, in equilibrium, the expected contestants' payoffs must be non-negative, that is, $E\left(u_{1}^{*}\right) \geq 0$ and $E\left(u_{2}^{*}\right) \geq 0$, which requires (see (5.B)) that

$$
(1-\alpha) \delta^{\alpha}+k^{\alpha} \geq 0 \text { and }(1-\alpha) k^{\alpha}+\delta^{\alpha} \geq 0
$$

Note that the conditions in (7.B) ensure that the SOC in (6.B) are also satisfied.

\footnotetext{
${ }^{16}$ Notice that the proof in our case where $0<\alpha \leq 2$ is not a straightforward extension of the proof of Proposition 1 in Epstein et al. (2011) where $0<\alpha \leq 1$. When $0<\alpha \leq 1$, (6B) and (7B) are automatically satisfied and, in turn, the second order conditions are satisfied and the utility of every contestant is not negative. However, when $1<\alpha \leq 2$, (6B) and (7B) are not automatically satisfied. Hence, in the current proof of Proposition 2, we have to take into account constraints that were not relevant when $0<\alpha \leq 1$, as pointed out in the sequel, see problem (8B).
} 
Now, anticipating the equilibrium efforts of the contestants, the designer's objective is to maximize $x_{1}^{*}+x_{2}^{*}=\frac{\alpha(\delta k)^{\alpha}\left(n_{1}+n_{2}\right)}{\left(k^{\alpha}+\delta^{\alpha}\right)^{2}}$. For $0<\alpha \leq 2$, the designer's problem is:

$$
\operatorname{Max}_{L}=\frac{\alpha(\delta k)^{\alpha}\left(n_{1}+n_{2}\right)}{\left(k^{\alpha}+\delta^{\alpha}\right)^{2}}
$$

s.t.

$$
\begin{aligned}
& (1-\alpha) \delta^{\alpha}+k^{\alpha} \geq 0 \\
& (1-\alpha) k^{\alpha}+\delta^{\alpha} \geq 0 \\
& \delta \geq 0
\end{aligned}
$$

The first two constraints ensure that the SOC for the equilibrium strategies of the two contestants are satisfied and that their expected payoffs are non-negative. Let us temporarily ignore these conditions and solve the designer's unconstrained problem in two stages. In the first stage, $\alpha$ is considered as given and $\delta$ is computed from the first order condition for the (unconstrained) maximization of $G_{L}$ :

$$
\frac{\partial G_{L}}{\partial \delta}=\frac{\alpha^{2} \delta^{\alpha-1} k^{\alpha}\left(n_{1}+n_{2}\right)\left(k^{\alpha}-\delta^{\alpha}\right)}{\left(k^{\alpha}+\delta^{\alpha}\right)^{3}}=0
$$

which yields

$$
\delta^{*}(\alpha)=k
$$

Substituting this value into $\frac{\partial^{2} G_{L}}{\partial \delta^{2}}$, we get that the SOC of the designer's problem is satisfied. That is,

$$
\frac{\partial^{2} G_{L}}{\partial \delta^{2}}=-\frac{\alpha^{3}\left(n_{1}+n_{2}\right)}{32 k^{3 \alpha+2}}<0
$$

Furthermore, the optimal bias in (10.B) also satisfies all the constraints of problem (8.B). $\delta^{*}(\alpha)=k$ is therefore the optimal bias for any $\alpha, 0<\alpha \leq 2$. Substituting $\delta^{*}(\alpha)=k$ in equations (3.B)-(5.B), we get that $x_{1}^{*}=0.25 \alpha n_{1}, x_{2}^{*}=0.25 \alpha n_{2}$, $p_{1}=p_{2}=0.5, \quad E\left(u_{1}^{*}\right)=0.25 n_{1}(2-\alpha), \quad E\left(u_{2}^{*}\right)=0.25 n_{2}(2-\alpha) \quad$ and 
$G_{L}=0.25 \alpha\left(n_{1}+n_{2}\right)$. This implies that $\alpha=2{ }^{17}$ is optimal for the designer yielding the maximal certain aggregate efforts of $G_{L}=0.5\left(n_{1}+n_{2}\right)$.

Q.E.D

${ }^{17}$ Notice that Nti (2004) has established that for the existence of a unique pure-strategy equilibrium when $k>1$ it must be the case that $\alpha<2$. In our case, we allow discrimination between the contestants. Therefore we obtain that even though $k>1$, in a unique pure-strategy equilibrium $\alpha=2$. 


\section{Bar-Ilan University \\ Department of Economics \\ WORKING PAPERS}

1-01 The Optimal Size for a Minority

Hillel Rapoport and Avi Weiss, January 2001.

2-01 An Application of a Switching Regimes Regression to the Study of Urban Structure

Gershon Alperovich and Joseph Deutsch, January 2001.

3-01 The Kuznets Curve and the Impact of Various Income Sources on the Link Between Inequality and Development

Joseph Deutsch and Jacques Silber, February 2001.

4-01 International Asset Allocation: A New Perspective

Abraham Lioui and Patrice Poncet, February 2001.

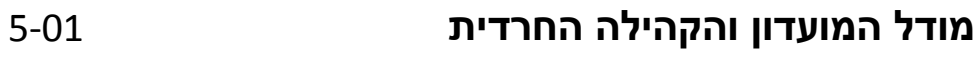

$$
\text { יעקב רוזנברג, פברואר } 2001 .
$$

6-01 Multi-Generation Model of Immigrant Earnings: Theory and Application Gil S. Epstein and Tikva Lecker, February 2001.

7-01 Shattered Rails, Ruined Credit: Financial Fragility and Railroad Operations in the Great Depression

Daniel A. Schiffman, February 2001.

8-01 Cooperation and Competition in a Duopoly R\&D Market

Damiano Bruno Silipo and Avi Weiss, March 2001.

9-01 A Theory of Immigration Amnesties

Gil S. Epstein and Avi Weiss, April 2001.

10-01 Dynamic Asset Pricing With Non-Redundant Forwards Abraham Lioui and Patrice Poncet, May 2001.

11-01 Macroeconomic and Labor Market Impact of Russian Immigration in Israel Sarit Cohen and Chang-Tai Hsieh, May 2001.

Electronic versions of the papers are available at http://www.biu.ac.il/soc/ec/wp/working_papers.html 
12-01 Network Topology and the Efficiency of Equilibrium Igal Milchtaich, June 2001.

13-01 General Equilibrium Pricing of Trading Strategy Risk Abraham Lioui and Patrice Poncet, July 2001.

14-01 Social Conformity and Child Labor Shirit Katav-Herz, July 2001.

15-01 Determinants of Railroad Capital Structure, 1830-1885 Daniel A. Schiffman, July 2001.

16-01 Political-Legal Institutions and the Railroad Financing Mix, 1885-1929 Daniel A. Schiffman, September 2001.

17-01 Macroeconomic Instability, Migration, and the Option Value of Education Eliakim Katz and Hillel Rapoport, October 2001.

18-01 Property Rights, Theft, and Efficiency: The Biblical Waiver of Fines in the Case of Confessed Theft

Eliakim Katz and Jacob Rosenberg, November 2001.

19-01 Ethnic Discrimination and the Migration of Skilled Labor Frédéric Docquier and Hillel Rapoport, December 2001.

1-02 Can Vocational Education Improve the Wages of Minorities and Disadvantaged Groups? The Case of Israel

Shoshana Neuman and Adrian Ziderman, February 2002.

2-02 What Can the Price Gap between Branded and Private Label Products Tell Us about Markups?

Robert Barsky, Mark Bergen, Shantanu Dutta, and Daniel Levy, March 2002.

3-02 Holiday Price Rigidity and Cost of Price Adjustment Daniel Levy, Georg Müller, Shantanu Dutta, and Mark Bergen, March 2002.

4-02 Computation of Completely Mixed Equilibrium Payoffs Igal Milchtaich, March 2002.

5-02 Coordination and Critical Mass in a Network Market - An Experimental Evaluation Amir Etziony and Avi Weiss, March 2002. 
6-02 Inviting Competition to Achieve Critical Mass

Amir Etziony and Avi Weiss, April 2002.

7-02 Credibility, Pre-Production and Inviting Competition in a Network Market Amir Etziony and Avi Weiss, April 2002.

8-02 Brain Drain and LDCs' Growth: Winners and Losers Michel Beine, Fréderic Docquier, and Hillel Rapoport, April 2002.

9-02 Heterogeneity in Price Rigidity: Evidence from a Case Study Using MicroLevel Data

Daniel Levy, Shantanu Dutta, and Mark Bergen, April 2002.

10-02 Price Flexibility in Channels of Distribution: Evidence from Scanner Data Shantanu Dutta, Mark Bergen, and Daniel Levy, April 2002.

11-02 Acquired Cooperation in Finite-Horizon Dynamic Games Igal Milchtaich and Avi Weiss, April 2002.

12-02 Cointegration in Frequency Domain Daniel Levy, May 2002.

13-02 Which Voting Rules Elicit Informative Voting? Ruth Ben-Yashar and Igal Milchtaich, May 2002.

14-02 Fertility, Non-Altruism and Economic Growth: Industrialization in the Nineteenth Century

Elise S. Brezis, October 2002.

15-02 Changes in the Recruitment and Education of the Power Elitesin Twentieth Century Western Democracies

Elise S. Brezis and François Crouzet, November 2002.

16-02 On the Typical Spectral Shape of an Economic Variable Daniel Levy and Hashem Dezhbakhsh, December 2002.

17-02 International Evidence on Output Fluctuation and Shock Persistence Daniel Levy and Hashem Dezhbakhsh, December 2002.

1-03 Topological Conditions for Uniqueness of Equilibrium in Networks Igal Milchtaich, March 2003.

2-03 Is the Feldstein-Horioka Puzzle Really a Puzzle? Daniel Levy, June 2003. 
3-03 Growth and Convergence across the US: Evidence from County-Level Data Matthew Higgins, Daniel Levy, and Andrew Young, June 2003.

4-03 Economic Growth and Endogenous Intergenerational Altruism Hillel Rapoport and Jean-Pierre Vidal, June 2003.

5-03 Remittances and Inequality: A Dynamic Migration Model Frédéric Docquier and Hillel Rapoport, June 2003.

6-03 Sigma Convergence Versus Beta Convergence: Evidence from U.S. CountyLevel Data

Andrew T. Young, Matthew J. Higgins, and Daniel Levy, September 2003.

7-03 Managerial and Customer Costs of Price Adjustment: Direct Evidence from Industrial Markets

Mark J. Zbaracki, Mark Ritson, Daniel Levy, Shantanu Dutta, and Mark Bergen, September 2003.

8-03 First and Second Best Voting Rules in Committees

Ruth Ben-Yashar and Igal Milchtaich, October 2003.

9-03 Shattering the Myth of Costless Price Changes: Emerging Perspectives on Dynamic Pricing

Mark Bergen, Shantanu Dutta, Daniel Levy, Mark Ritson, and Mark J. Zbaracki, November 2003.

1-04 Heterogeneity in Convergence Rates and Income Determination across U.S. States: Evidence from County-Level Data

Andrew T. Young, Matthew J. Higgins, and Daniel Levy, January 2004.

2-04 "The Real Thing:" Nominal Price Rigidity of the Nickel Coke, 1886-1959 Daniel Levy and Andrew T. Young, February 2004.

3-04 Network Effects and the Dynamics of Migration and Inequality: Theory and Evidence from Mexico

David Mckenzie and Hillel Rapoport, March 2004.

4-04 Migration Selectivity and the Evolution of Spatial Inequality Ravi Kanbur and Hillel Rapoport, March 2004.

5-04 Many Types of Human Capital and Many Roles in U.S. Growth: Evidence from County-Level Educational Attainment Data

Andrew T. Young, Daniel Levy and Matthew J. Higgins, March 2004. 
6-04 When Little Things Mean a Lot: On the Inefficiency of Item Pricing Laws Mark Bergen, Daniel Levy, Sourav Ray, Paul H. Rubin and Benjamin Zeliger, May 2004.

7-04 Comparative Statics of Altruism and Spite Igal Milchtaich, June 2004.

8-04 Asymmetric Price Adjustment in the Small: An Implication of Rational Inattention

Daniel Levy, Haipeng (Allan) Chen, Sourav Ray and Mark Bergen, July 2004.

1-05 Private Label Price Rigidity during Holiday Periods Georg Müller, Mark Bergen, Shantanu Dutta and Daniel Levy, March 2005.

2-05 Asymmetric Wholesale Pricing: Theory and Evidence Sourav Ray, Haipeng (Allan) Chen, Mark Bergen and Daniel Levy, March 2005.

3-05 Beyond the Cost of Price Adjustment: Investments in Pricing Capital Mark Zbaracki, Mark Bergen, Shantanu Dutta, Daniel Levy and Mark Ritson, May 2005.

4-05 Explicit Evidence on an Implicit Contract Andrew T. Young and Daniel Levy, June 2005.

5-05 Popular Perceptions and Political Economy in the Contrived World of Harry Potter

Avichai Snir and Daniel Levy, September 2005.

6-05 Growth and Convergence across the US: Evidence from County-Level Data (revised version)

Matthew J. Higgins, Daniel Levy, and Andrew T. Young, September 2005.

1-06 Sigma Convergence Versus Beta Convergence: Evidence from U.S. CountyLevel Data (revised version)

Andrew T. Young, Matthew J. Higgins, and Daniel Levy, June 2006.

2-06 Price Rigidity and Flexibility: Recent Theoretical Developments Daniel Levy, September 2006.

3-06 The Anatomy of a Price Cut: Discovering Organizational Sources of the Costs of Price Adjustment

Mark J. Zbaracki, Mark Bergen, and Daniel Levy, September 2006. 
4-06 Holiday Non-Price Rigidity and Cost of Adjustment

Georg Müller, Mark Bergen, Shantanu Dutta, and Daniel Levy.

September 2006.

2008-01 Weighted Congestion Games With Separable Preferences

Igal Milchtaich, October 2008.

2008-02 Federal, State, and Local Governments: Evaluating their Separate Roles in US Growth

Andrew T. Young, Daniel Levy, and Matthew J. Higgins, December 2008.

2008-03 Political Profit and the Invention of Modern Currency

Dror Goldberg, December 2008.

2008-04 Static Stability in Games

Igal Milchtaich, December 2008.

2008-05 Comparative Statics of Altruism and Spite

Igal Milchtaich, December 2008.

2008-06 Abortion and Human Capital Accumulation: A Contribution to the Understanding of the Gender Gap in Education

Leonid V. Azarnert, December 2008.

2008-07 Involuntary Integration in Public Education, Fertility and Human Capital

Leonid V. Azarnert, December 2008.

2009-01 Inter-Ethnic Redistribution and Human Capital Investments

Leonid V. Azarnert, January 2009.

2009-02 Group Specific Public Goods, Orchestration of Interest Groups and Free Riding

Gil S. Epstein and Yosef Mealem, January 2009.

2009-03 Holiday Price Rigidity and Cost of Price Adjustment

Daniel Levy, Haipeng Chen, Georg Müller, Shantanu Dutta, and Mark Bergen, February 2009.

2009-04 Legal Tender

Dror Goldberg, April 2009.

2009-05 The Tax-Foundation Theory of Fiat Money

Dror Goldberg, April 2009. 
2009-06 The Inventions and Diffusion of Hyperinflatable Currency

Dror Goldberg, April 2009.

2009-07 The Rise and Fall of America's First Bank

Dror Goldberg, April 2009.

2009-08 Judicial Independence and the Validity of Controverted Elections

Raphaël Franck, April 2009.

2009-09 A General Index of Inherent Risk

Adi Schnytzer and Sara Westreich, April 2009.

2009-10 Measuring the Extent of Inside Trading in Horse Betting Markets

Adi Schnytzer, Martien Lamers and Vasiliki Makropoulou, April 2009.

2009-11 The Impact of Insider Trading on Forecasting in a Bookmakers' Horse Betting Market

Adi Schnytzer, Martien Lamers and Vasiliki Makropoulou, April 2009.

2009-12 Foreign Aid, Fertility and Population Growth: Evidence from Africa Leonid V. Azarnert, April 2009.

2009-13 A Reevaluation of the Role of Family in Immigrants' Labor Market Activity: Evidence from a Comparison of Single and Married Immigrants Sarit Cohen-Goldner, Chemi Gotlibovski and Nava Kahana, May 2009.

2009-14 The Efficient and Fair Approval of "Multiple-Cost-Single-Benefit" Projects Under Unilateral Information Nava Kahanaa, Yosef Mealem and Shmuel Nitzan, May 2009.

2009-15 Après nous le Déluge: Fertility and the Intensity of Struggle against Immigration

Leonid V. Azarnert, June 2009.

2009-16 Is Specialization Desirable in Committee Decision Making?

Ruth Ben-Yashar, Winston T.H. Koh and Shmuel Nitzan, June 2009.

2009-17 Framing-Based Choice: A Model of Decision-Making Under Risk

Kobi Kriesler and Shmuel Nitzan, June 2009.

2009-18 Demystifying the 'Metric Approach to Social Compromise with the Unanimity Criterion'

Shmuel Nitzan, June 2009. 
2009-19 On the Robustness of Brain Gain Estimates

Michel Beine, Frédéric Docquier and Hillel Rapoport, July 2009.

2009-20 Wage Mobility in Israel: The Effect of Sectoral Concentration

Ana Rute Cardoso, Shoshana Neuman and Adrian Ziderman, July 2009.

2009-21 Intermittent Employment: Work Histories of Israeli Men and Women, 1983-1995

Shoshana Neuman and Adrian Ziderman, July 2009.

2009-22 National Aggregates and Individual Disaffiliation: An International Study

Pablo Brañas-Garza, Teresa García-Muñoz and Shoshana Neuman, July 2009.

2009-23 The Big Carrot: High-Stakes Incentives Revisited

Pablo Brañas-Garza, Teresa García-Muñoz and Shoshana Neuman, July 2009.

2009-24 The Why, When and How of Immigration Amnesties

Gil S. Epstein and Avi Weiss, September 2009.

2009-25 Documenting the Brain Drain of "la Crème de la Crème»: Three Case-Studies on International Migration at the Upper Tail of the Education Distribution

Frédéric Docquier and Hillel Rapoport, October 2009.

2009-26 Remittances and the Brain Drain Revisited: The Microdata Show That More Educated Migrants Remit More

Albert Bollard, David McKenzie, Melanie Morten and Hillel Rapoport, October 2009.

2009-27 Implementability of Correlated and Communication Equilibrium Outcomes in Incomplete Information Games Igal Milchtaich, November 2009.

2010-01 The Ultimatum Game and Expected Utility Maximization - In View of Attachment Theory

Shaul Almakias and Avi Weiss, January 2010.

2010-02 A Model of Fault Allocation in Contract Law - Moving From Dividing Liability to Dividing Costs

Osnat Jacobi and Avi Weiss, January 2010. 
2010-03 Coordination and Critical Mass in a Network Market: An Experimental Investigation

Bradley J. Ruffle, Avi Weiss and Amir Etziony, February 2010.

2010-04 Immigration, fertility and human capital: A model of economic decline of the West

Leonid V. Azarnert, April 2010.

2010-05 Is Skilled Immigration Always Good for Growth in the Receiving Economy?

Leonid V. Azarnert, April 2010.

2010-06 The Effect of Limited Search Ability on the Quality of Competitive Rent-Seeking Clubs

Shmuel Nitzan and Kobi Kriesler, April 2010.

2010-07 Condorcet vs. Borda in Light of a Dual Majoritarian Approach

Eyal Baharad and Shmuel Nitzan, April 2010.

2010-08 Prize Sharing in Collective Contests

Shmuel Nitzan and Kaoru Ueda, April 2010.

2010-09 Network Topology and Equilibrium Existence in Weighted Network Congestion Games

Igal Milchtaich, May 2010.

2010-10 The Evolution of Secularization: Cultural Transmission, Religion and Fertility Theory, Simulations and Evidence

Ronen Bar-El, Teresa García-Muñoz, Shoshana Neuman and Yossef Tobol, June 2010.

2010-11 The Economics of Collective Brands

Arthur Fishman, Israel Finkelstein, Avi Simhon and Nira Yacouel, July 2010.

2010-12 Interactions Between Local and Migrant Workers at the Workplace

Gil S. Epstein and Yosef Mealem, August 2010.

2010-13 A Political Economy of the Immigrant Assimilation: Internal Dynamics

Gil S. Epstein and Ira N. Gang, August 2010.

2010-14 Attitudes to Risk and Roulette

Adi Schnytzer and Sara Westreich, August 2010. 
2010-15 Life Satisfaction and Income Inequality

Paolo Verme, August 2010.

2010-16 The Poverty Reduction Capacity of Private and Public Transfers in Transition

Paolo Verme, August 2010.

2010-17 Migration and Culture

Gil S. Epstein and Ira N. Gang, August 2010.

2010-18 Political Culture and Discrimination in Contests

Gil S. Epstein, Yosef Mealem and Shmuel Nitzan, October 2010.

2010-19 Governing Interest Groups and Rent Dissipation

Gil S. Epstein and Yosef Mealem, November 2010.

2010-20 Beyond Condorcet: Optimal Aggregation Rules Using Voting Records

Eyal Baharad, Jacob Goldberger, Moshe Koppel and Shmuel Nitzan, December 2010.

2010-21 Price Points and Price Rigidity

Daniel Levy, Dongwon Lee, Haipeng (Allan) Chen, Robert J. Kauffman and Mark Bergen, December 2010.

2010-22 Price Setting and Price Adjustment in Some European Union

Countries: Introduction to the Special Issue

Daniel Levy and Frank Smets, December 2010.

2011-01 Business as Usual: A Consumer Search Theory of Sticky Prices and Asymmetric Price Adjustment

Luís Cabral and Arthur Fishman, January 2011.

2011-02 Emigration and democracy

Frédéric Docquier, Elisabetta Lodigiani, Hillel Rapoport and Maurice Schiff, January 2011.

2011-03 Shrinking Goods and Sticky Prices: Theory and Evidence

Avichai Snir and Daniel Levy, March 2011.

2011-04 Search Costs and Risky Investment in Quality

Arthur Fishman and Nadav Levy, March 2011. 
2011-05 To What Extent do Investors in a Financial Market Anchor Their Judgments? Evidence from the Hong Kong Horserace Betting Market Johnnie E.V. Johnson, Shuang Liu and Adi Schnytzer, March 2011.

2011-06 Attitudes to Risk and Roulette

Adi Schnytzer and Sara Westreich, March 2011.

2011-07 False Consciousness in Financial Markets: Or is it in Ivory Towers? Adi Schnytzer and Sara Westreich, March 2011.

2011-08 Herding in Imperfect Betting Markets with Inside Traders

Adi Schnytzer and Avichai Snir, March 2011.

2011-09 Painful Regret and Elation at the Track

Adi Schnytzer and Barbara Luppi, March 2011.

2011-10 The Regression Tournament: A Novel Approach to Prediction Model Assessment

Adi Schnytzer and Janez Šušteršič, March 2011.

2011-11 Shorting the Bear: A Test of Anecdotal Evidence of Insider Trading in Early Stages of the Sub-Prime Market Crisis

Les Coleman and Adi Schnytzer, March 2011.

2011-12 SP Betting as a Self-Enforcing Implicit Cartel

Adi Schnytzer and Avichai Snir, March 2011.

2011-13 Testing for Home Team and Favorite Biases in the Australian Rules Football Fixed Odds and Point Spread Betting Markets

Adi Schnytzer and Guy Weinberg, March 2011.

2011-14 The Impact of Insider Trading on Forecasting in a Bookmakers' Horse Betting Market

Adi Schnytzer, Martien Lamers and Vasiliki Makropoulou, March 2011.

2011-15 The Prediction Market for the Australian Football League

Adi Schnytzer, March 2011.

2011-16 Information and Attitudes to Risk at the Track

Adi Schnytzer and Sara Westreich, March 2011.

2011-17 Explicit Evidence on an Implicit Contract

Andrew T. Young and Daniel Levy, March 2011. 
2011-18 Globalization, Brain Drain and Development

Frédéric Docquier and Hillel Rapoport, March 2011.

2011-19 The Impact of Worker Effort on Public Sentiment Towards Temporary Migrants

Gil S. Epstein and Alessandra Venturini, April 2011.

2011-20 Animal Modeling of Earthquakes and Prediction Markets

Adi Schnytzer and Yisrael Schnytzer, May 2011.

2011-21 A Field Study of Social Learning

Arthur Fishman and Uri Gneezy, May 2011.

2011-22 MD Dialog on: Optimum Savings and Optimal Growth: the CassMalinvaud-Koopmans Nexus

Stephen E. Spear and Warren Young, May 2011.

2011-23 Privilege-Seeking Activities in Organizational Politics and Its Effect on More Productive Employees

Gil S. Epstein and Bruce C. Herniter, August 2011.

2011-24 Integrated Public Education, Fertility and Human Capital Leonid V. Azarnert, August 2011.

2011-25 Male vs. Female Guest-Worker Migration: Does it Matter for Fertility in the Source Country?

Leonid V. Azarnert, August 2011.

2011-26 Tradable Immigration Quotas

Jesús Fernández-Huertas Moraga and Hillel Rapoport, September 2011.

2011-27 Remittances, Migrants' Education and Immigration Policy: Theory and Evidence from Bilateral Data

Frédéric Docquier, Hillel Rapoport and Sara Salomone, October 2011.

2011-28 Cooperation and Effort in Group Contests

Gil S. Epstein and Yosef Mealem, November 2011.

2011-29 Lotteries vs. All-Pay Auctions in Fair and Biased Contests

Gil S. Epstein, Yosef Mealem and Shmuel Nitzan, November 2011. 